\title{
Numerical Analysis on the Bending Performance of Prestressed Superposing-Poured Composite Beams
}

\author{
Jianmin Wang $\mathbb{D},{ }^{1,2}$ Chengfeng Zhu, ${ }^{1}$ Ziqiang Xiao, ${ }^{1}$ Qijun Zhao, ${ }^{1}$ and Junzhe Liu $\mathbb{D D}^{3}$ \\ ${ }^{1}$ School of Civil and Environmental Engineering, Ningbo University, Ningbo 315211, China \\ ${ }^{2}$ Key Laboratory of Impact and Safety Engineering, Ministry of Education, Ningbo University, Ningbo 315211, China \\ ${ }^{3}$ School of Architecture Engineering, Qingdao Agricultural University, Qingdao 266109, China \\ Correspondence should be addressed to Jianmin Wang; wangjianmin@nbu.edu.cn and Junzhe Liu; liujunzhe@nbu.edu.cn
}

Received 6 June 2020; Revised 20 July 2020; Accepted 10 August 2020; Published 29 August 2020

Academic Editor: Peng Zhang

Copyright (c) 2020 Jianmin Wang et al. This is an open access article distributed under the Creative Commons Attribution License, which permits unrestricted use, distribution, and reproduction in any medium, provided the original work is properly cited.

\begin{abstract}
Aiming at the bending performance of the prestressed superposing-poured concrete beam, the numerical simulation on the composite beams poured with the normal weight concrete (NWC) superposed on the fibred ceramsite lightweight aggregate concrete (LWAC) was conducted. Three kinds of prestressing schemes, straight linear prestressing force, curved prestressing force not across the casting interface, and curved prestressing force across the casting interface, were simulated for comparison, and the influence of the casting interval time was also considered. Results indicate that the stiffness of the superposing-poured beam can be effectively strengthened by considered schemes of the prestressing force; in addition, there are certain increases on the ultimate load except imposing the straight linear prestressing force. As the curved prestressing force is imposed across the casting interface, the maximal interlayer slip of the casting interfacial transition zone (C-ITZ) approximately equals to that without the prestressing force. The scalar stiffness degradation (SDEG) of the C-ITZ for the casting interval time being 14 days is obvious because of the weakening on the bonding performance of the C-ITZ. Comparatively, the SDEG variation of the C-ITZ in the model with the curved prestressing force across the casting interface is smoother and smaller on the whole than the other two prestressed schemes for the case of the casting interval time being 14 days.
\end{abstract}

\section{Introduction}

Ceramsite lightweight aggregate concrete (LWAC) possesses the merit with higher strength relative to lighter density, which benefits from the ceramsite characterizing lighter apparent density and rough surface with many small opening holes. The density of LWAC is lighter than that of the normal weight concrete (NWC) for about $25 \%-30 \%$. In addition, LWAC shows good performance such as the thermal insulation [1-3]. The developing of the prefabricated building technology puts forward higher requirements to the composite concrete members and the functionally graded concrete (FGC) members. Generally, the composite concrete members are composed of the precast and the cast in-situ components. For the composite concrete and FGC, the interfacial bonding performance is prominent to guarantee the integration and compatibility of whole members. Lightweight aggregate can effectively improve the microstructure of the interface in concrete and make the interfacial transition zone (ITZ) more compact because of its own morphological structure and apparent pores [4]. Akmaluddin and Murtiadi [5] discussed the connection behaviour of the composite concrete precast column and the sandwich beam under the static loading. Campi and Monetto [6,7] proposed a closed solution of two-layer beams considering the interlayer slip, in which a linear and nonproportional law relating interfacial shear tractions and slips was chosen to describe the interfacial behaviour. Iskhakov et al. [8,9] studied the mechanical property of prestressed composite beams and proposed a new concept that considers the interlayer deformation of concrete in the tension and compression zones. Ji et al. [10] analyzed the change rule of the midspan deflection of prestressed reactive powder concrete (RPC) and the NWC composite beams 
considering the influence of the prestressing degree, the RPC height, and the NC strength; the higher the prestressing degree is, the longer the elastic stage before crack is, and the faster the stiffness in strengthening stage after the yielding decreases. Study indicates that the application of prestressing can improve the rigidity of composite beams and reduce the cracks $[11,12]$. Wu et al. [13] studied the failure mechanism, flexural capacity, short-term stiffness, and crack distribution of U-shaped and inverted T-shaped prestressed composite beams and pointed out that composite beams with natural rough surface can be analyzed as whole beams not considering the relative slip. Li and Ji [14] analyzed the developing law of the crack during the loading of prestressed composite beams considering different prestressing degrees and prefabricated component heights. Li et al. [15] studied the interfacial bonding performance of the prestressed composite beams with different stirrup spaces and pointed out that the smaller the stirrup spacing is, the less possible the bonding slip occurs on the casting interface.

The related research are mainly focused on the overall performance of composite members composed of NWC without prestressing or only with straight linear prestressing force. Moreover, different casting interval times are necessary to suit the constructional variety of the superposingpoured composite members. The imposing of the prestressing force can effectively increase the stiffness of the concrete beams. Because of the existing of the casting interfacial transition zone (C-ITZ) in the superposed composite beams, the mechanism and performance of the composite beams after exerting the prestressing force is complicated. Besides, the arrangement of the prestressed bars and the casting interval time are great importance to the performance of the composite beams [16]. In this paper, the numerical simulation was conducted on the mechanical performance of the composite beams poured with the NWC superposed on the ceramsite LWAC. Different arrangement ways of prestressed bars and casting interval times were specially discussed on the influence of the overall performance of the superposing-poured beams.

\section{Simulation Modelling}

2.1. Modelling Scheme. The simulation analysis is based on the bending experiment of the simplified supported superposing-poured beams composed of the ceramsite LWAC and NWC. The precast ceramsite LWAC component at the bottom of the beam mainly bears the tensile force under the experimental load, and the NWC is casted on the LWAC component late. The detailed parameters of the superposingpoured beams are shown in Figure 1, in which the sectional casting height are determined according to the neutral axis in the section of the composite beams. The description on the prestressing schemes and the casting interval time are listed in Table 1. There are eight superposing-poured beam models designed for simulation, in which six models are prestressed superposing-poured beams, and the other two ordinary beams models are based on the experiment used for comparison. The grades of the longitudinal bars and the stirrups bars are HRB400 and HRB300, respectively. The prestressing bars are 1860 grade $1 \times 7$ stranded wire, and the prestressing force is $30 \mathrm{kN}$.

2.2. Material Constitutive Relationship in the Model. The concrete damaged plasticity model (CDP) is used to simulate the mechanical properties of superposing-poured concrete beams in this paper. It describes the inelastic performance of concrete based on the isotropic damage elasticity together with the isotropic stretching and compression damage plasticity. Besides, the CDP model can effectively simulate the dynamic and static mechanical behaviour of the concrete $[17,18]$. The mix ratio of the two kinds of concrete in the experimental members B1-1 and B1-2 are listed in Table 2, and the basic mechanical properties of the concrete and reinforced bars are listed in Tables 3 and 4 .

The C-ITZ is a typical part zone in the composite beams, which has significant influence on the overall performance of the composite beams. The mechanical property of the C-ITZ is related to the treatment method of the casting interface, the casting interval time, two kinds of concrete materials, and so on. The manual chiselling method was adopted to handle the casting interface in the referring experiment [19]. The cohesive element is used in the model to simulate the C-ITZ in the superposing-poured beam model. The basic mechanical parameters of the cohesive element listed in Table 5 are determined according to the experimental data [16] and the relevant formula [20, 21].

2.3. Model Building. In the model, the concrete and reinforced bars are modelled using the solid element and link element, respectively. Among them, the reduced integral element C3D8R is assigned to simulate the concrete, and the T3D2 truss element is assigned to simulate the reinforced bars in the model. The C-ITZ between the LWAC and NWC in the stackpoured beams are simulated by the cohesive elements. The local rigid bodies are modelled at the loading point and bearings to avoid the stress concentration during the simulation. The boundary constraints and loading scheme are shown in Figure 1 and are identical to the experiment [19].

The application of the prestressing force in the model is realized by the cooling method in the temperature field corresponding to the initial state. In the subsequent analysis step, the prestressing strand shrinks as the temperature reduces to generate the pretension force. The temperature cooling value is determined according to the following formula [22]:

$$
\Delta T=\frac{F}{\alpha E A}=\frac{\sigma}{\alpha E},
$$

in which $F$ is the prestressing force, $\sigma$ is the prestressing stress, $A$ is the cross-sectional area, $E$ is the elastic modulus, and $\alpha$ is the linear expansion coefficient.

\section{Simulation Results}

3.1. Modelling Verification. The effectiveness of the modelling was first verified by comparing the simulation results of B1-1 and B1-2 with that of the experiment. The loadmidspan deflection is shown in Figure 2. The modelling 


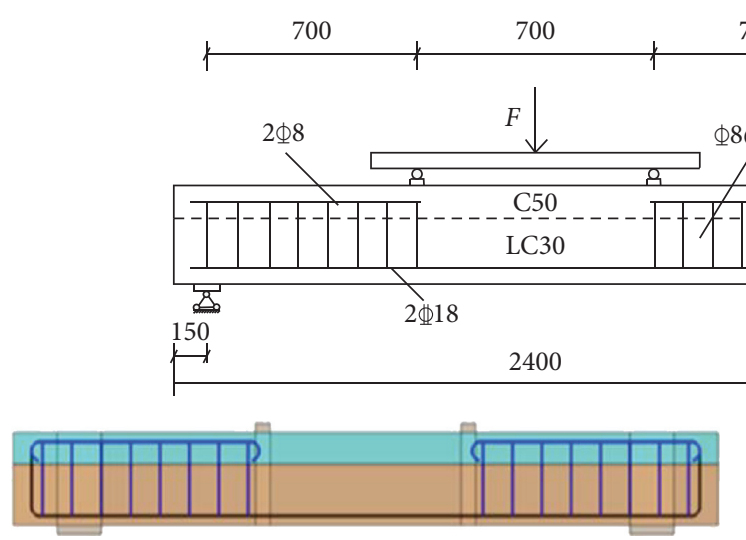

B1-1, B1-2

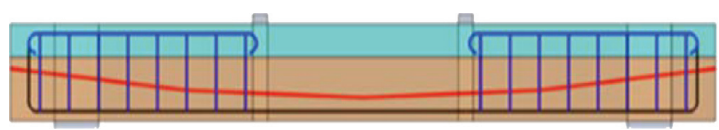

B3-1, B3-2
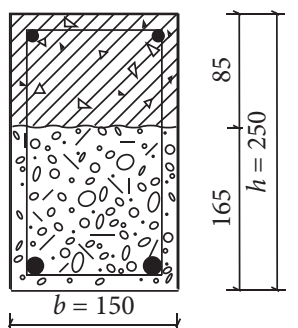

FIGURE 1: Scheme of the superposing-poured beam model.

TABLE 1: Description of the superposing-poured beam model.

\begin{tabular}{lcc}
\hline Model no. & Prestressing schemes & Casting interval time \\
\hline B1-1* & Superposing-poured beams no prestress & 45 minutes \\
B1-2* & Superposing-poured beams with straight linear prestressed bars & 45 minutes \\
B2-1 & & 14 days \\
B2-2 & Superposing-poured beams with curved prestressed bars not across the casting interface & 45 minutes \\
B3-1 & & 14 days \\
B3-2 & Superposing-poured beams with curved prestressed bars across the casting interface & 45 minutes \\
B4-1 & B4-2 & 14 days \\
\hline
\end{tabular}

*For modelling comparison based on the experiment.

TABLE 2: Mix ratio of LWAC and NWC of the experiment [19].

\begin{tabular}{|c|c|c|c|c|c|c|c|}
\hline \multirow{2}{*}{ Concrete } & \multicolumn{6}{|c|}{$\left(\mathrm{kg} / \mathrm{m}^{3}\right)$} & \multirow{2}{*}{ Reinforcement ratio (\% } \\
\hline & Ceramsite & Crushed stone & Sand & Cement & Fly ash & Water & \\
\hline LC30 & 820 & - & 510 & 440 & 80 & 237 & \multirow{2}{*}{1.52} \\
\hline $\mathrm{C} 40$ & - & 1180 & 580 & 400 & 80 & 200 & \\
\hline
\end{tabular}

TABLE 3: Mechanical parameters of the concrete from the experiment [19].

\begin{tabular}{lccccc}
\hline Concrete & $f_{\text {cu }}(\mathrm{MPa})$ & $f_{\text {ck }}(\mathrm{MPa})$ & $f_{\mathrm{t}}(\mathrm{MPa})$ & $E_{\mathrm{c}}(\mathrm{MPa})$ & $\mathrm{Density}\left(\mathrm{kg} / \mathrm{m}^{3}\right)$ \\
\hline LWAC/LC30 & 36.2 & 32.0 & 3.2 & $2.55 \times 10^{4}$ & 1740 \\
NWC/C50 & 56.1 & 47.4 & 4.3 & $3.55 \times 10^{4}$ & 2400 \\
\hline
\end{tabular}

TABLE 4: Mechanical parameters of reinforced bars [16].

\begin{tabular}{lccc}
\hline Types of bars & Diameter $(\mathrm{mm})$ & Yielding strength $(\mathrm{MPa})$ & Ultimate strength $(\mathrm{MPa})$ \\
\hline Stirrups & 8 & 364.8 & 564 \\
Hanger bars & 8 & 364.8 & 564 \\
Longitudinal bars & 20 & 455.1 & 580 \\
Prestressing bars* & 9.5 & 1395 & 1860 \\
\hline
\end{tabular}

${ }^{*}$ Referring to the code for design of concrete structures (GB 50010-2010). 
TABLE 5: Parameters of the cohesive element to simulate the C-ITZ.

\begin{tabular}{lccccc}
\hline Casting interval time & $\begin{array}{c}\text { Modulus } E \\
(\mathrm{GPa})\end{array}$ & $\begin{array}{c}\text { Density } \rho \\
\left(\mathrm{kg} / \mathrm{m}^{3}\right)\end{array}$ & $\begin{array}{c}\text { Elastic stiffness } K_{\mathrm{n}} \\
\left(\mathrm{N} / \mathrm{mm}^{3}\right)\end{array}$ & $\begin{array}{c}\text { Cohesion strength } \sigma_{\mathrm{n}} \\
(\mathrm{MPa})\end{array}$ & $\begin{array}{c}\text { Fracture energy } G_{f} \\
(\mathrm{~N} / \mathrm{mm})\end{array}$ \\
\hline 45 minutes & 23 & 2100 & $10^{6}$ & 3.2 & 0.033 \\
14 days & 23 & 2100 & $10^{6}$ & 2.0 & 0.027 \\
\hline
\end{tabular}

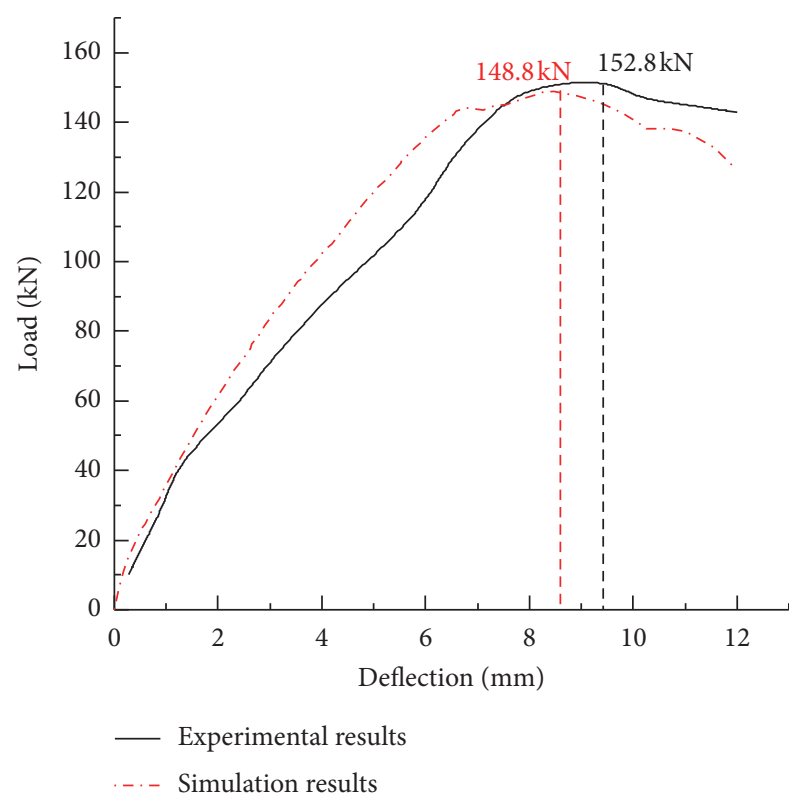

(a)

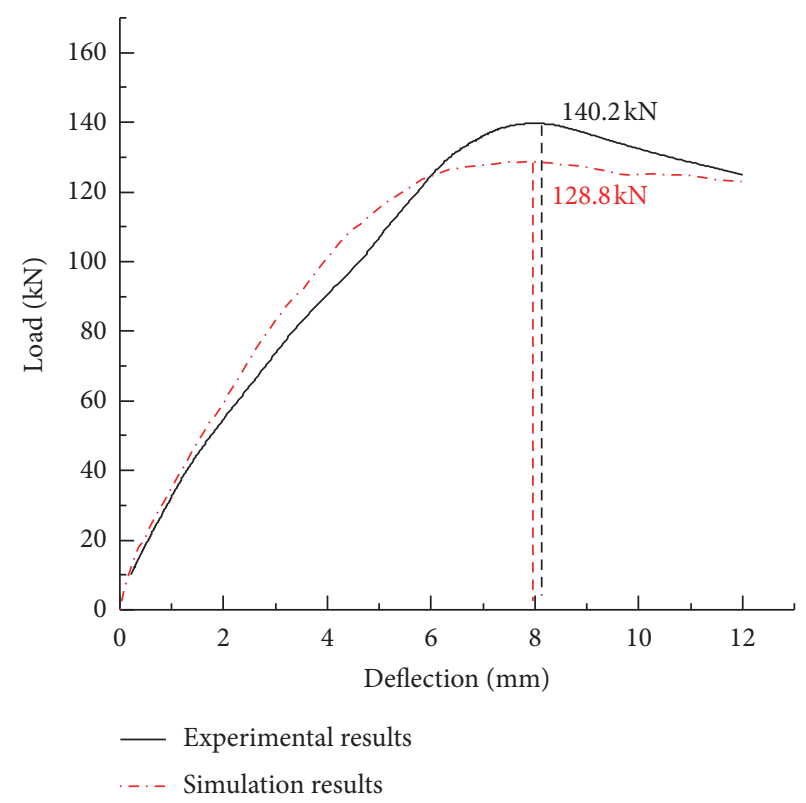

(b)

FIGURE 2: Load-deflection relationship of B1-1 and B1-2. (a) B1-1. (b) B1-2.

results fit well with that from the experiment before the yielding except that the deflection is a little smaller than that of the experiment. This difference becomes obvious during the loading late stage. It is mainly because of the typical influence of the generation of macrocracks in the experiment members as the load increases. Besides, the yielding loads are a little lower than that of the experiment. Considering the variation of the casting interval times, the ultimate load of model B1-2 is lower than that of B1-1 whether from the experiment or from the simulation. It is because the bonding performance of C-ITZ in the superposing-poured beams is weakened as the casting interval time increases. The emerging and developing of the cracks in the model can be represented by the compressive and tensile damage factors of the concrete element, which are shown in Figure 3. The cracks distribution result from the simulation coincides well with that of the experimental result.

At the loading beginning stage, the vertical bending cracks first emerge in the midspan bottom bending zone. The bending cracks develop upward with the loading. At the same time, diagonal cracks also emerge near both two foot bearings and incline upward to the loading points. One important characteristic is that most cracks have a brief stop as they develop close to the C-ITZ. This can be verified both by the experimental and the simulating results. Subsequently, only some cracks develop across the
C-ITZ as the load continually increases. Finally, the beam failures due to the yielding of the longitudinal reinforcement and the concrete crack are at the top of the midspan.

In addition, the simulation on the prestressing is verified by comparing the simulation results of B2-1, B3-1, and B4-1 with results from the corresponding calculation method and design codes. The prestressing effect can be represented by the equivalent load method: The effect of straight linear prestressing and curved prestressing are equivalent to the pure bending and uniformly distributed load, respectively. Due to a certain difference existing in the elastic module between LWAC and NWC, the ceramsite LWAC is first converted into NWC by the equivalent section converting method. The inverse arch deflections of the superposingpoured beam model are calculated according to the bendingmoment-area method. At the same time, the inverse arch deflections of the straight prestressing and the curved prestressing are calculated $[23,24]$ :

$$
\begin{gathered}
f_{\mathrm{Z}}=\frac{N_{\mathrm{po}} e L^{2}}{8 E_{\mathrm{c}} I_{\mathrm{o}}}, \\
f_{\mathrm{Q}}=\frac{5 N_{\mathrm{po}} e L^{2}}{48 E_{\mathrm{c}} I_{\mathrm{o}}},
\end{gathered}
$$



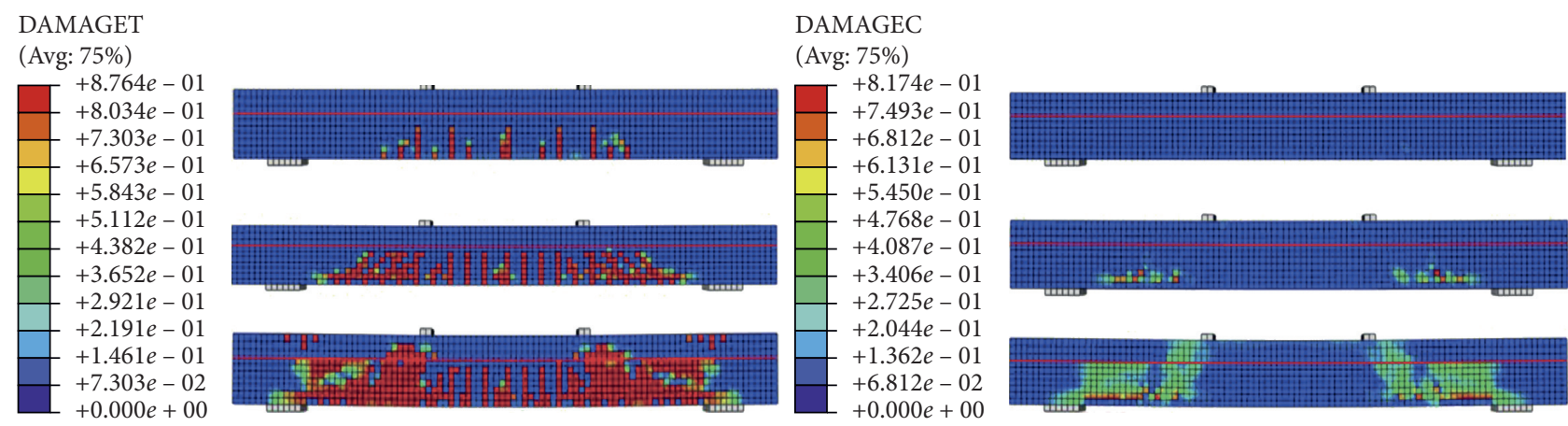

(a)
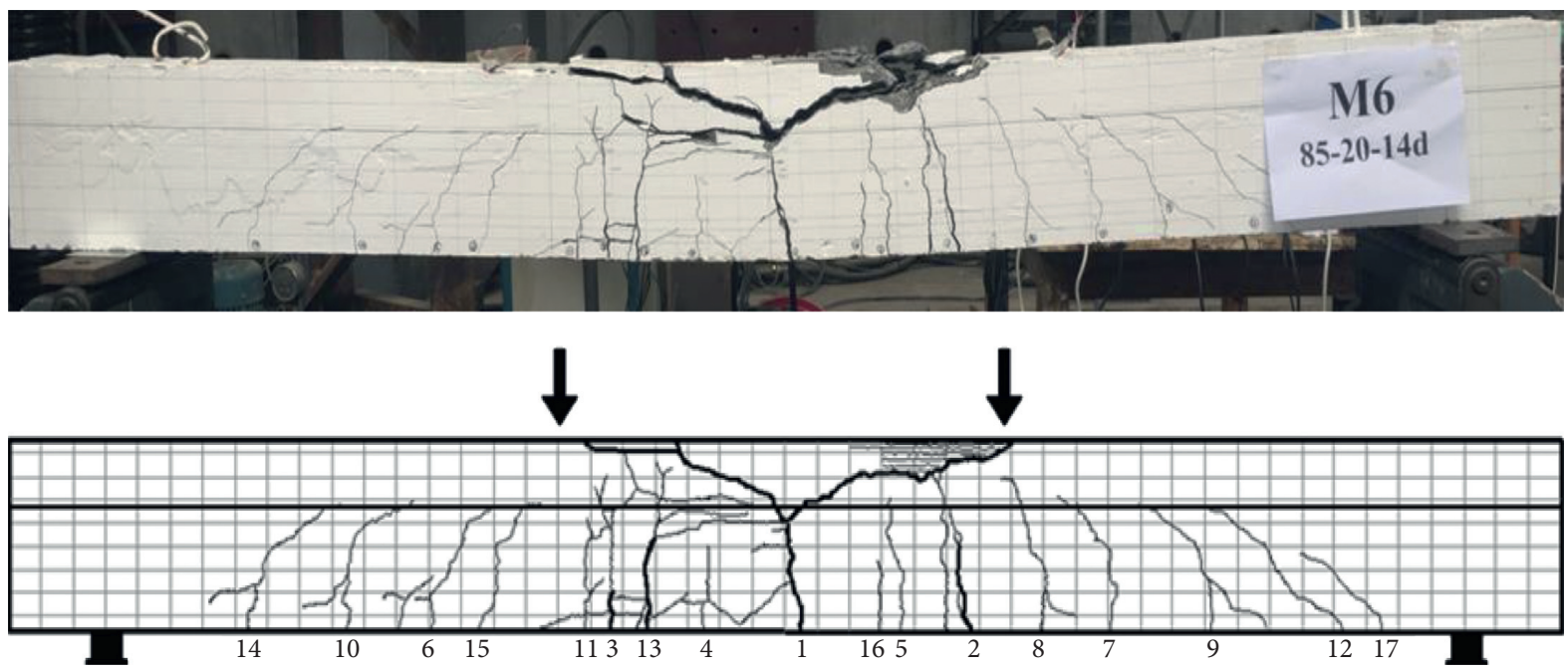

(b)

FIgURE 3: Comparison of cracks distribution of B1-2. (a) The tensile and compressive damage nephogram from the simulation.(b) Experimental beam.

where $N_{\text {po }}$ is the effective prestressing force, $e$ is the eccentricity from the center of prestressed bars to the neutral axis of the converted section, $L$ is the span length, $E_{\mathrm{c}}$ is the elastic modulus, and $I_{\mathrm{o}}$ is the inertial moment of the converted section.

The comparison of the results is listed in Table 6. The simulation results are close to that from the referring calculation method and design codes on the whole. Compared with the bending-moment-area method and ACI318-99, it is shown that the result from GB50010-2002 is more reliable due to the stiffness reduction during calculating.

3.2. Load-Deflection Relationship. The load-deflection curves of the superposing-poured beams are shown in Figure 4. Compared with B1-1 and B1-2 without the prestressing force, the midspan deflections of beams with different arrangement modes of prestressed bars are all lower before the yielding load. In addition, there are observable increases on the ultimate loads of beams with prestressed bars except that of B2-1 and B2-2. Compared with the straight linear prestressing scheme at the bottom of the beam, the increases on the ultimate loads of beams with curved prestressed bars are more obvious for different casting interval times.

The simulation results are listed in Table 7. For B2-1 and B2-2 exerting the straight linear prestressing force at the bottom of beams, there is no obvious increasing on the ultimate load compared with B1-1 and B1-2, respectively. But the midspan deflection is clearly smaller than that of B11 and B1-2, respectively. The reduction of the deflection is about $23 \%$ and $19.9 \%$ that of $\mathrm{B} 1-1$ and $\mathrm{B} 1-2$, respectively. At the same time, the induced inverted arch deflection at the midspan are largest among the three kinds of prestressing schemes.

For the scheme with curved prestressed bars not across the C-ITZ, the ultimate load of B3-1 is clearly increased about $8.7 \%$ compared with B1-1 while the deflection is reduced about $8.0 \%$. Comparatively, the ultimate load of B32 is increased about $12.5 \%$ compared with that of B1-2 with the midspan deflection reduced about $7.0 \%$. It is due to the weakening of the bonding performance of the C-ITZ in the superposing-poured beams, which has significant influence on the deformation of the beam as the load increases. Because the bonding shear performance of the C-ITZ in the superposing-poured beams decreases quickly as the casting interval time increases, and the remaining shear strength 
TABLE 6: Comparison of the inverse arch deflections of the prestressing force.

\begin{tabular}{lcccccc}
\hline \multirow{2}{*}{ Model no. } & Simulation results & \multicolumn{2}{c}{ Moment-area method } & \multicolumn{2}{c}{ GB50010-2010 } & \multicolumn{2}{c}{ ACI318-99 } \\
& $f(\mathrm{~mm})$ & $f_{1}(\mathrm{~mm})$ & $f_{1} / f$ & $f_{2}(\mathrm{~mm})$ & $f_{2} / f$ & $f_{3}(\mathrm{~mm})$ \\
\hline B2-1 & 0.192 & 0.184 & 0.958 & 0.216 & 1.125 & 0.184 \\
B3-1 & 0.177 & 0.158 & 0.893 & 0.223 & 1.260 & 0.189 \\
B4-1 & 0.179 & 0.174 & 0.972 & 0.246 & 1.374 & 0.209 \\
\hline
\end{tabular}

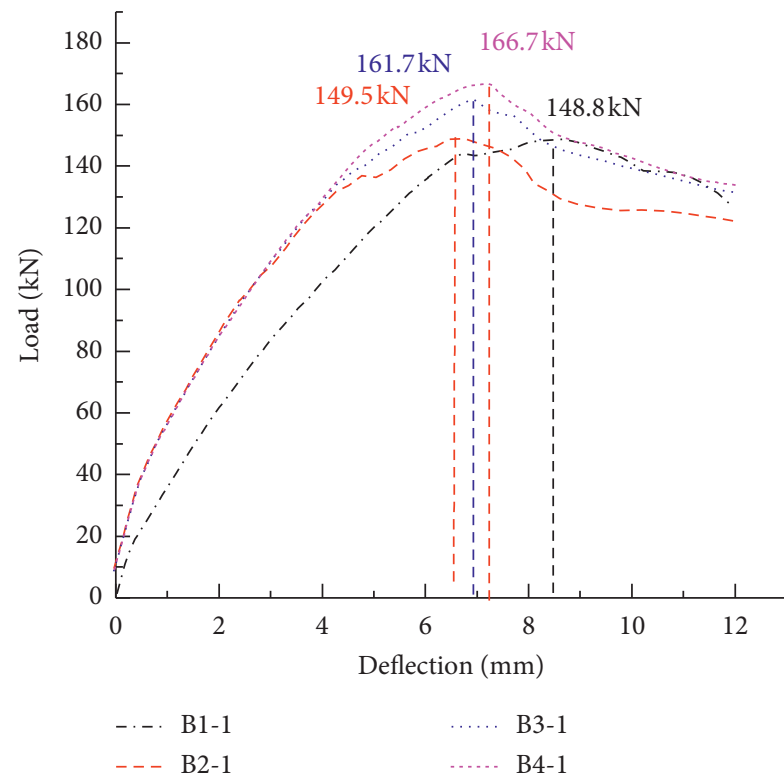

(a)

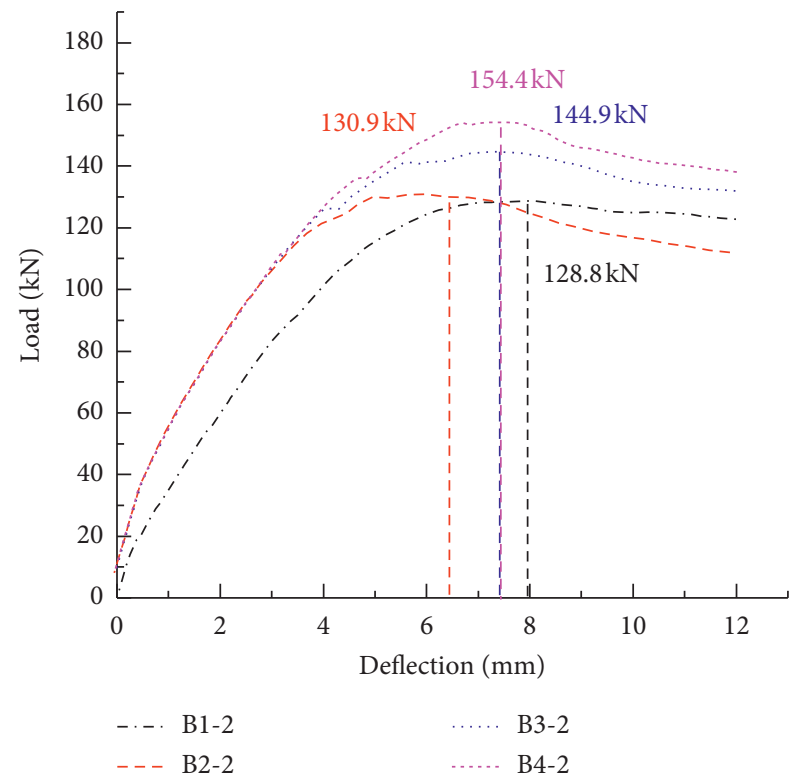

(b)

FIGURE 4: Load-deflection curves of the beam model. (a) 45 minutes casting interval time. (b) 14 days casting interval time.

TABLE 7: Simulation results of the model.

\begin{tabular}{lccc}
\hline Model & Inverse arch deflection, $f(\mathrm{~mm})$ & Ultimate loads $(\mathrm{kN})$ & Deflection $(\mathrm{mm})$ \\
\hline B1-1 & - & 148.8 & 8.61 \\
B2-1 & 0.192 & 149.5 & 6.63 \\
B3-1 & 0.177 & 161.7 & 6.92 \\
B4-1 & 0.179 & 166.7 & 7.12 \\
B1-2 & - & 128.8 & 7.99 \\
B2-2 & 0.191 & 130.9 & 6.40 \\
B3-2 & 0.179 & 144.9 & 7.43 \\
B4-2 & 0.184 & 154.4 & 7.42 \\
\hline
\end{tabular}

with the casting interval time being 14 days is about $40 \%$ that casting at the same time [24].

As the curved prestressed bars in the superposingpoured beam models are located across the C-ITZ for the model B4-1 and B4-2, the increase extent of the ultimate loads is $12.0 \%$ and $19.9 \%$, respectively, compared with B1-1 and B1-2. At the same time, the midspan deflections are similar to that of B3-1 and B3-2, respectively.

3.3. Relative Slip in the C-ITZ. The cohesive element are adopted to simulate the performance of C-ITZ in the superposing-poured beams. The relative longitudinal slip of the C-ITZ outside the loading point is extracted as shown in Figure 5 for discussion. Whether there is or no prestressing force, the relative slip of C-ITZ in the beam that the casting interval time is 45 minutes is much smaller than that with the casting interval time being 14 days as the load increases. The final maximal relative slip value for all models is listed in Table 8.

For B2-1 and B2-2 exerted the straight linear prestressing force, the final relative slip value is 1.8 times and 2.05 times as large as that of $\mathrm{B} 1-1$ and $\mathrm{B} 1-2$, respectively, and the relative slip in the C-ITZ both of B1-2 and B2-2 characterizes continual and accelerated increasing with regards to the loading until the final failure.

As imposed, the curved prestressing force with the casting interval time being 45 minutes, the overall variation 


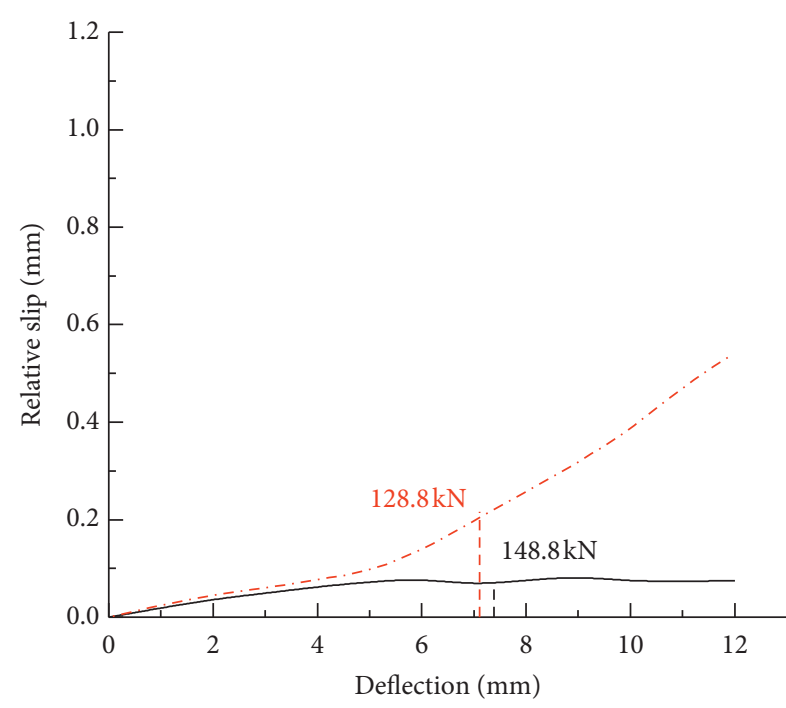

- B1-1

-... B1-2

(a)

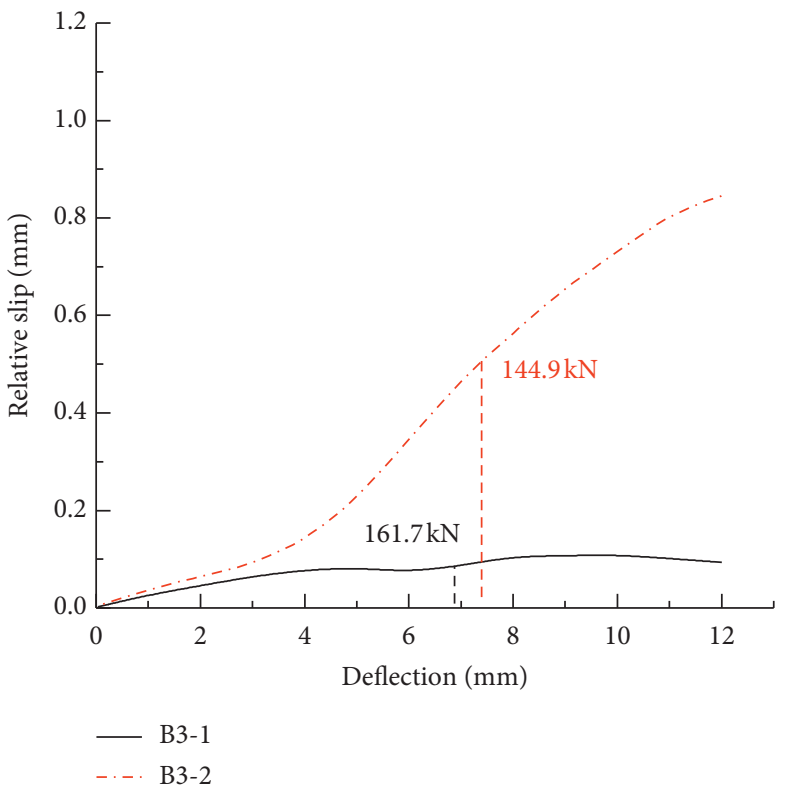

(c)

Figure 5: Relative slip of the C-ITZ. (a) B1-1and B1-2. (b) B2-1 and B2-2. (c) B3-1and B3-2. (d) B4-1 and B4-2.

TABLE 8: Maximal relative slip in C-ITZ.

\begin{tabular}{lc}
\hline Model no. & Relative slip $(\mathrm{mm})$ \\
\hline B1-1 & 0.075 \\
B2-1 & 0.135 \\
B3-1 & 0.094 \\
B4-1 & 0.072 \\
B1-2 & 0.542 \\
B2-2 & 1.114 \\
B3-2 & 0.846 \\
B4-2 & 0.574 \\
\hline
\end{tabular}

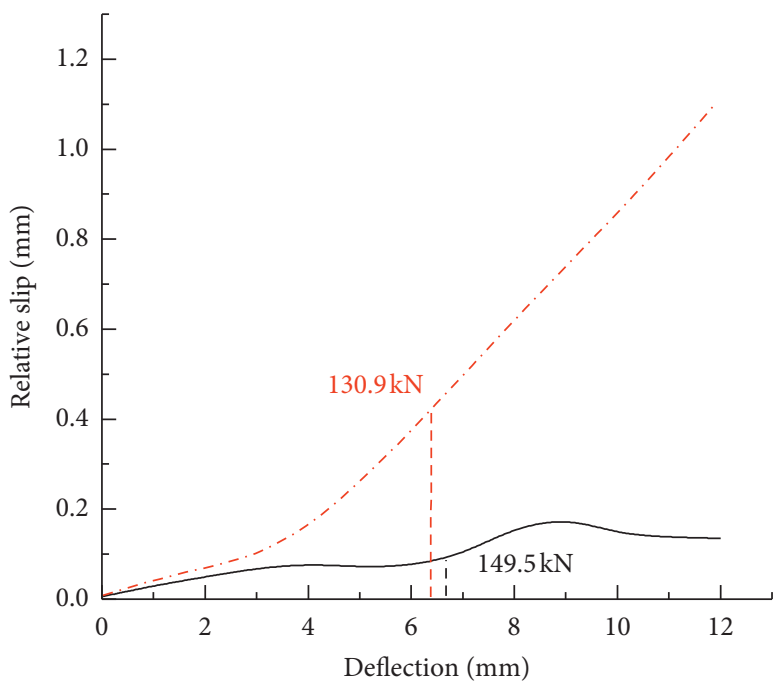

- B2-1

-... B2-2

(b)

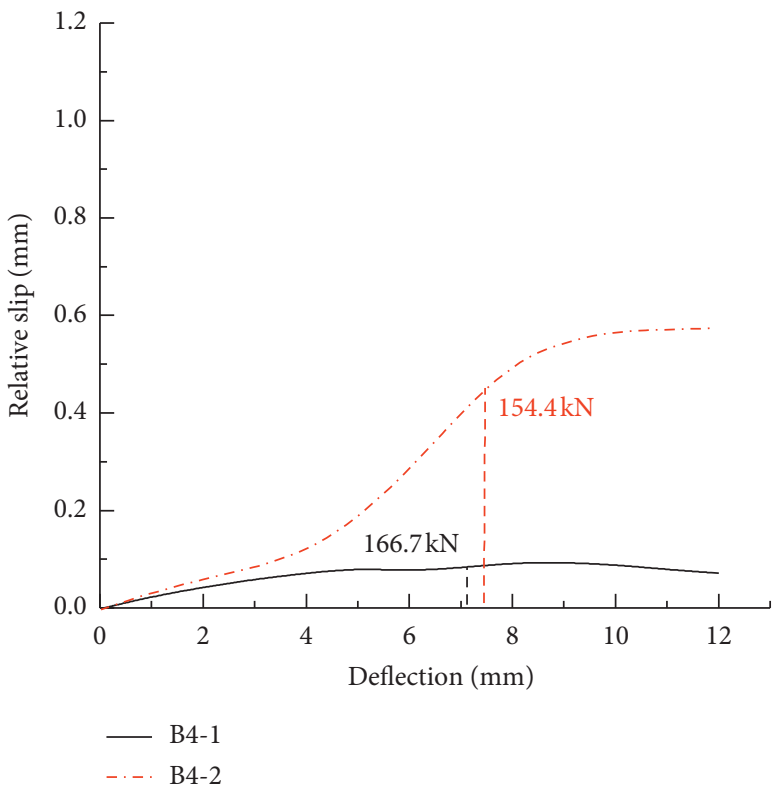

(d)

of the relative slip with regard to the loading for B3-1 and B4-1 is similar to that of B1-1. The final maximal relative slip of $\mathrm{B} 3-1$ is about $125 \%$ that of $\mathrm{B} 1-1$. Comparatively, this value of B4-1 is almost similar to that of B1-1. For the casting interval time being 14 days with the curved prestressing force, a significant characteristic for the variation relation of the relative slip with the loading is that the increase of the relative slip eases up after yielding both for B3-2 and B4-2. The possible reason is that the moment distribution generated by the curved prestressing force in the beam is similar to that from the experimental load. After the yielding of the 
SDEG

(Avg: 75\%)

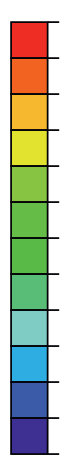

$+9.725 e-0$
$+8.915 e-0$
$+8.104 e-0$
$+7.294 e-0$
$+6.483 e-0$
$+5.673 e-0$
$+4.863 e-0$
$+4.052 e-0$
$+3.242 e-0$
$+2.431 e-0$
$+1.621 e-0$
$+8.104 e-0$
$+0.000 e+00$
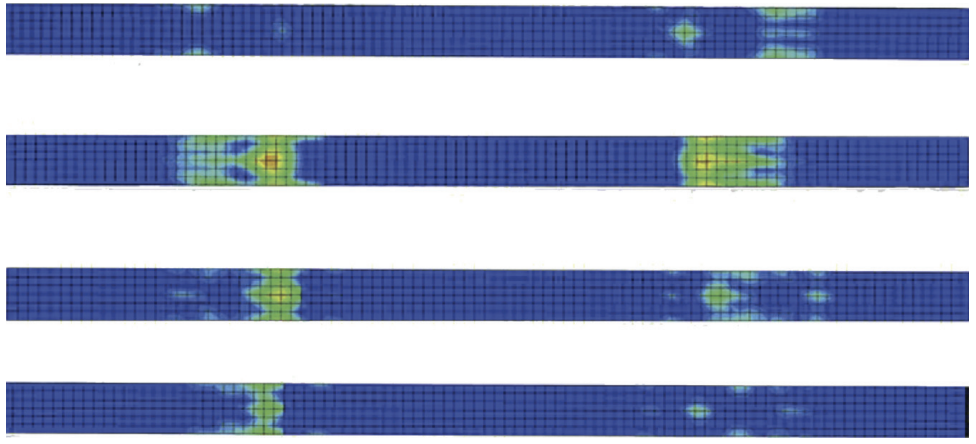

(a)

SDEG

(Avg: 75\%)

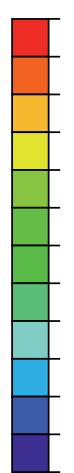

$+9.664 e-01$

$+8.858 e-01$

$+8.053 e-01$

$+7.248 e-01$

$+6.442 e-01$

$+5.637 e-01$

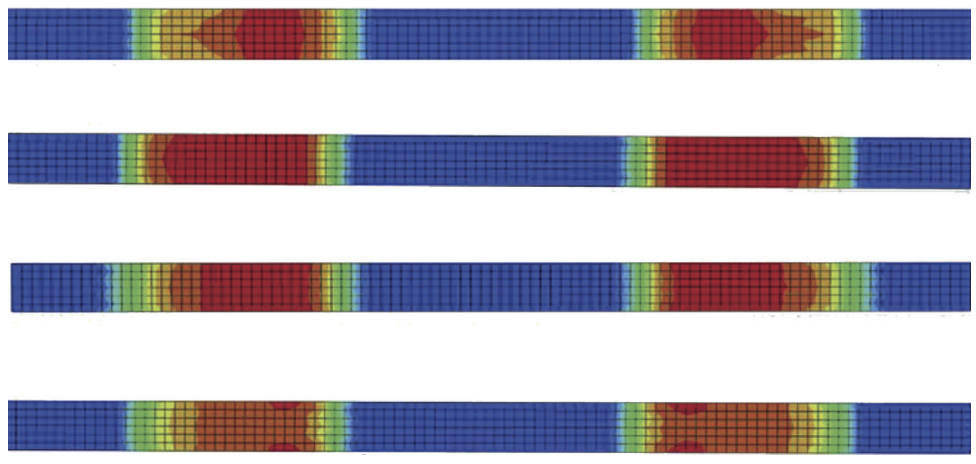

$+4.832 e-01$

$+4.027 e-01$

$+3.221 e-01$

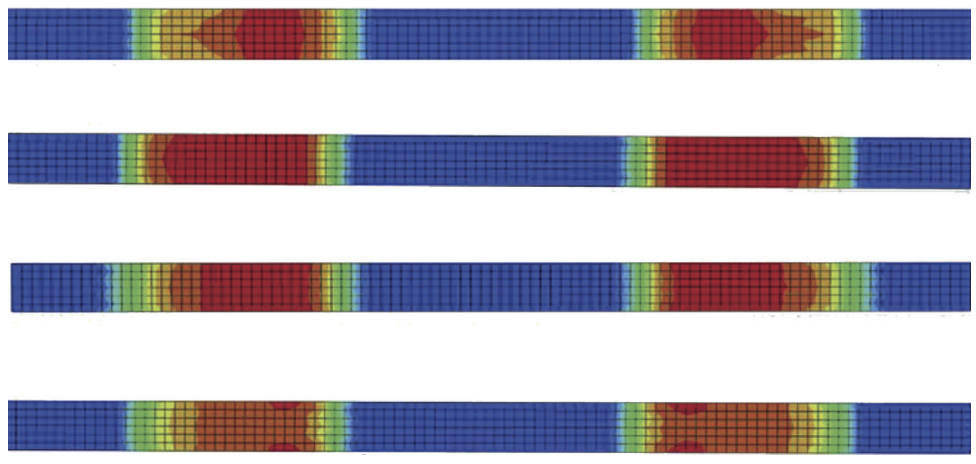

$+2.416 e-01$

$+1.611 e-01$

$+8.053 e-02$

$+0.000 e+00$

(b)

Figure 6: SDEG distribution of C-ITZ at the ultimate load state. (a) B1-1, B2-1, B3-1, and B4-1. (b) B1-2, B2-2, B3-2, and B4-2.

longitudinal bars, the existing of the curved prestressing force effectively slow down the developing of the relative slip in the C-ITZ. Finally, the maximal relative slip value of B3-2 is about $156 \%$ that of B1-2. Comparatively, the maximal relative slip value of $\mathrm{B} 4-2$ is almost similar to that of B1-2.

3.4. Stiffness Degradation of the C-ITZ. The key for superposing-poured beams to perform with well-collaborative behaviour is whether there is excellent working compatibility and adhesion in the C-ITZ. The performance of the C-ITZ is influenced by the constructional method of the casting interface, the difference in the elastic module and strengths between the two kinds of concretes together with the casting interval time, and so on. The scalar stiffness degradation (SDEG) of the cohesive elements in the modelling can be extracted to symbolically characterize the damage variation in the C-ITZ. SDEG equaling 0 indicates that there is no damage, and SDEG equaling 1 means the cohesive elements are in full failure. The SDEG diagrams of cohesive elements to simulate the C-ITZ in the modelling at the ultimate load state are shown in Figure 6. The mainly prominent region is located in the shear span near the loading point. For cases of the casting interval time being 45 minutes, there is a larger region with higher SDEG values emerged in B2-1 compared with B1-1, B3-1, and B4-1. The possible reason is the arrangement of the curved prestressing force in B3-1 and B4-1 approximate the bending moment diagrams under the designed load, which make the coordinated performance of the superposing-poured beam model better than that of B2-1.

Compared with the situation of the casting interval time being 45 minutes, the region with higher SDEG values are more obvious for all beam models with the casting interval time being 14 days. It is due to that the bonding shear strength of the C-ITZ decreases to $40 \%$ with the casting interval time being 45 minutes. Results indicate that the distribution range and the SDEG values of B4-2 are generally similar to that of B1-2 from Figure 6(b). In addition, the distribution of SDEG values in B4-2 is smoother than that in B1-2. Comparatively, the area range with higher SDEG values in B3-2 and B2-2 are larger, especially for B2-2. Similarly, the SDEG values of B2-2 are generally larger than that in B3-2 and B4-2.

The SDEG variation of the C-ITZ corresponding to the loading is shown in Figure 7, in which the data are extracted and averaged from the SDEG distribution area with relatively higher values. The increase of SDEG in B2-1 is much larger than that of $\mathrm{B} 1-1, \mathrm{~B} 3-1$, and $\mathrm{B} 4-1$ for cases with the casting interval time being 45 minutes. Comparatively, the 


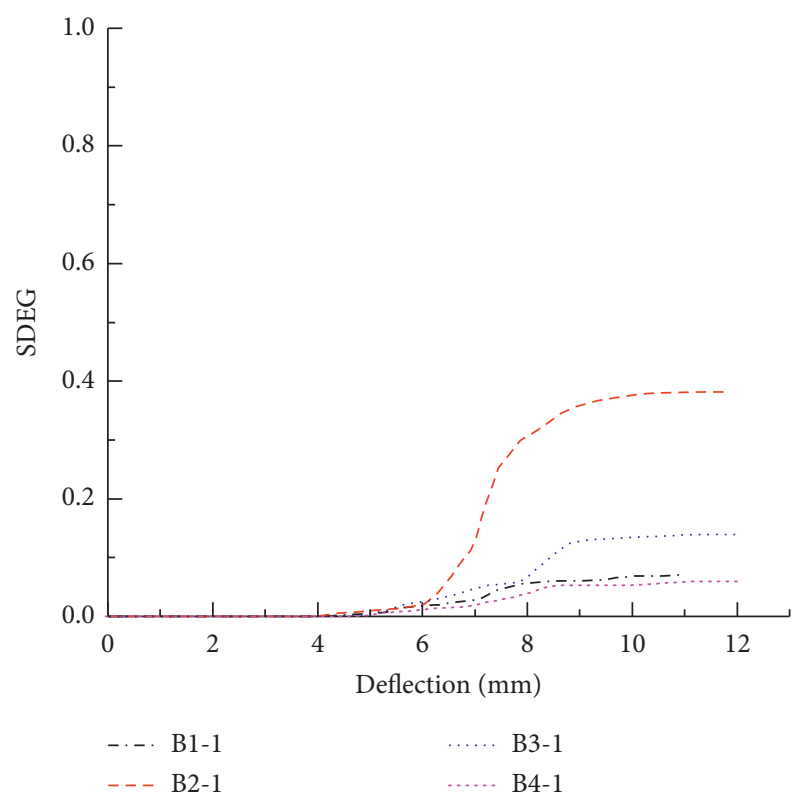

(a)

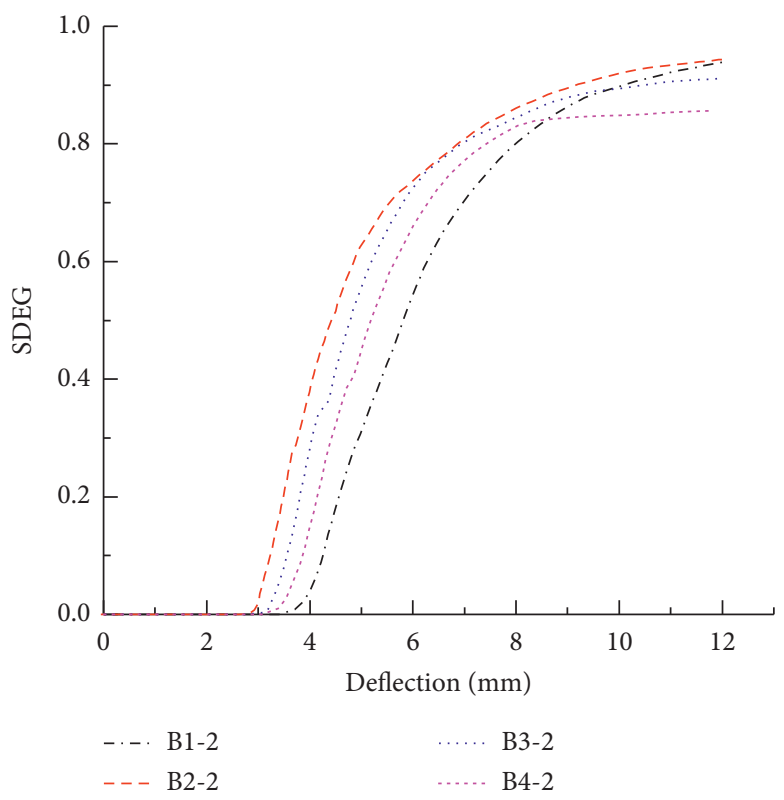

(b)

FIGURE 7: SDEG curves of stack-poured beams. (a) 45 minutes casting interval time. (b) 14 days casting interval time.

TABLE 9: Slipping loads and ultimate loads of beam models.

\begin{tabular}{lccc}
\hline Model no. & Slipping load $(\mathrm{kN})$ & Ultimate load $(\mathrm{kN})$ & Ratio $L_{\mathrm{R}}(\%)$ \\
\hline B1-1 & 108.2 & 148.8 & 72.7 \\
B2-1 & 129.1 & 149.5 & 86.4 \\
B3-1 & 134.5 & 161.7 & 83.2 \\
B4-1 & 142.5 & 166.7 & 85.5 \\
B1-2 & 91.6 & 128.8 & 70.7 \\
B2-2 & 101.5 & 130.9 & 77.5 \\
B3-2 & 108.4 & 144.9 & 74.8 \\
B4-2 & 111.3 & 154.4 & 72.1 \\
\hline
\end{tabular}

SDEG variation of B4-1 with regard to the loading is similar to that of B1-1.

For the casting interval time being 14 days, the variation of the SDEG of B2-2, B3-2, and B4-2 with regard to the loading are similar. The midspan deflection of B2-2, B3-2, and B4-2 as the SDEG begin to increase clearly is smaller than that of B1-2 due to the effect of the inverse arch from the prestress. Comparatively, the SDEG of B4-2 changes smoothly, and it is smaller than that of B2-2 and B3-2 on the whole.

The slipping load of the beam model is defined here as the load when the SDEG value of the C-ITZ is not zero and begins to change obviously. The slipping load of all beam models is listed in Table 9 together with the ratio of the slipping load to the ultimate load $L_{\mathrm{R}}$. After exerting the prestressing force, the slipping loads and the ratio $L_{\mathrm{R}}$ all increase for all beam models. As the casting interval time changes from 45 minutes to 14 days, the slipping load all decrease whether there is or no prestressing force. In addition, the ratio $L_{\mathrm{R}}$ also decreases. For both two casting interval time cases, the increased degree of the slipping load and the ultimate load for the curved prestressing force across the casting interface are larger than that of the other two considered schemes of the prestressing force.

\section{Conclusions}

The bending performance of the superposing-poured composite concrete beams was analyzed considering the influence with different prestressing schemes and different casting interval times.

(1) For the schemes imposing the straight linear prestressing force, the stiffness of the superposingpoured beam can be effectively strengthened, but there is little influence on the ultimate load. Comparatively, with the curved prestressing force imposed, there is observable increase on the ultimate load of the superposing-poured beam at the time of the stiffness effectively strengthened.

(2) The relative slip of the C-ITZ is obvious as the casting interval time changes from 45 minutes to 14 days because of the weakening on the bonding performance of the C-ITZ. Imposing the straight linear prestressing force further obviously increases the relative slip. Comparatively, the variation relationship of the relative slip with regards to the loading as imposing the curved prestressing force across the C-ITZ is more rational, which eases up after the yielding load of the beam. And the final maximal relative slip is similar to that with no prestressing force whether the casting interval time is 45 minutes or 14 days.

(3) When the casting interval time changes from 45 minutes to 14 days, the region with higher SDEG value at the ultimate state expands obviously whether there is or no prestressing force imposed. As imposed the straight linear prestress or the curved prestress but not across the casting interface, the region with higher SDEG value in the C-ITZ is larger 
than that with no prestress. Comparatively, when the curved prestressed bars are arranged across the C-ITZ, the region with higher SDEG value is similar to that with no the prestress; and the distribution of the SDEG are relatively uniform.

It is shown that more rational effect and performance can be obtained with the curved prestressing force across the casting interface exerted in the composite beams if it is practicable in the real construction. There is important influence on the mechanical performance of the superposing-poured composite beams as imposing the prestressing force. The possible interlayer slip and the stiffness degradation in the casting interfacial zone need further experimental analysis based on the numerical simulation.

\section{Data Availability}

The data used to support the findings of this study are available from the corresponding author upon request.

\section{Conflicts of Interest}

The authors declare that there are no conflicts of interest regarding the publication of this paper.

\section{Acknowledgments}

This work was supported by the National Natural Science Foundation of China (Nos. 51878360 and 51778302), Natural Science Foundation of Zhejiang Province (LY18E080008), and Ningbo Science and Technology Project (202002N3117).

\section{References}

[1] S. H. Dong, W. C. Yang, Y. Ge et al., "Mechanical properties of concrete containing ceramsite sand," in Proceedings of the Fifth International Conference on Transportation Engineering, pp. 1259-1265, Dalian, China, 2015.

[2] Q. X. Wang, Y. X. Shi, J. B. Shi et al., "An experimental study on thermal conductivity of ceramsite cellular concrete," in Proceedings of the International Conference On Structural, pp. 64-69, Atlantis Press, Dalian, China, 2015.

[3] X. Zhang, D. Deng, and J. Yang, "Mechanical properties and conversion relations of strength indexes for stone/sandlightweight aggregate concrete," Advances in Materials Science and Engineering, vol. 2018, Article ID 5402953, 12 pages, 2018.

[4] P. Vargas, O. Restrepo-Baena, and J. I. Tobón, "Microstructural analysis of interfacial transition zone (ITZ) and its impact on the compressive strength of lightweight concretes," Construction and Building Materials, vol. 137, pp. 381-389, 2017.

[5] Akmaluddin and S. Murtiadi, "Hybrid precast concrete column and sandwich concrete beam under static loading," Procedia Engineering, vol. 54, pp. 286-298, 2013.

[6] F. Campi and I. Monetto, "Numerical analysis of two-layer beams with interlayer slip and step-wise linear interface law," Engineering Structures, vol. 144, pp. 201-209, 2017.

[7] F. Campi and I. Monetto, "Analytical solutions of two-layer beams with interlayer slip and bi-linear interface law," International Journal of Solids and Structures, vol. 50, no. 5, pp. 687-698, 2013.
[8] I. Iskhakov and Y. Ribakov, "A design method for two-layer beams consisting of normal and fibered high strength concrete," Materials \& Design, vol. 28, no. 5, pp. 1672-1677, 2007.

[9] I. Iskhakov, Y. Ribakov, K. Holschemacher et al., "Experimental investigation of full scale two-layer reinforced concrete beams," Mechanics of Composite Materials \& Structures, vol. 21, no. 4, pp. 273-283, 2014.

[10] W. Y. Ji, W. W. Li, M. L. Guo et al., "Experimentation and calculation methods of prestressed RPC-NC composite beam deflection," Journal of Jilin University (Engineering and Technology Edition), vol. 48, no. 1, pp. 129-136, 2018.

[11] C. J. Zeng, Experimental Study on Bending Behavior and Design Methods of Prestressed Concrete Composite Beams, Hunan University, Changsha, China, 2005.

[12] X. G. Wang, L. Qiao, and Z. D. Shang, "Experimental study on flexural behavior of partially pre-stressed concrete composite beams subjected to service load," Journal of Liaoning Technical University (Natural Science), vol. 27, no. 1, pp. 69-72, 2008.

[13] F. B. Wu, H. L. Huang, X. H. Zhou et al., "Experimental study on flexural behavior of prestressed precast component composite beams," Journal of Building Structures, vol. 32, no. 5, pp. 107-115, 2011.

[14] W. W. Li and W. Y. Ji, "Experimental study of cracks in prestressed RPC-NC composite beams," Bridge Construction, vol. 47, no. 1, pp. 59-64, 2017.

[15] S. Q. Li, W. W. Wang, S. Wan et al., "Experimental study on bond behavior of interface between old and new concrete composite beam under pre-stressing forces," Engineering Mechanics, vol. 26, no. 6, pp. 141-146, 2009.

[16] A. Q. Liu, Y. M. Wang, J. M. Wang et al., "Experiment on the bonding performance of fibred ceramsite aggregate concrete and normal concrete," Journal of Ningbo University (NSEE), vol. 29, no. 4, pp. 92-95, 2016.

[17] P. Grassl, D. Grégoire, L. Rojas Solano, and G. PijaudierCabot, "Meso-scale modelling of the size effect on the fracture process zone of concrete," International Journal of Solids and Structures, vol. 49, no. 13, pp. 1818-1827, 2012.

[18] T. Yu, J. G. Teng, Y. L. Wong, and S. L. Dong, "Finite element modeling of confined concrete-II: plastic-damage model," Engineering Structures, vol. 32, no. 3, pp. 680-691, 2010.

[19] A. Q. Liu, Experimental Study on Bonding Behavior of Fiber Ceramsite Concrete Composite Members, Ningbo University, Ningbo, China, 2017.

[20] L. G. Huang, The Analysis of Cohesive Zone Model and UserDefined Subroutine Development in Finite Element Method, Zhengzhou University, Zhengzhou, China, 2010.

[21] J. F. Kou, F. Xu, J. P. Guo et al., "Damage laws of cohesive zone model and selection of the parameters," Journal of Mechanical Strength, vol. 33, no. 5, pp. 714-718, 2011.

[22] L. He and J. L. Wang, "Method of equivalent load and temperature reduction on prestressing tendon for effective prestress simulation," Journal of Highway and Transportation Research and Development, vol. 32, no. 11, pp. 75-80, 2015.

[23] L. M. Zhang, S. B. Zhao, and C. K. Huang, "Experimentation and calculation of deflection of prestressed high-performance concrete beams," Journal of Dalian University of Technology, vol. 45, no. 1, pp. 96-101, 2005.

[24] Y. T. Zhang, Y. Z. Sun, and Z. Z. Zhang, "Study on deflection calculation of prestressed reinforced concrete beams," Journal of Huazhong University of Science and Technology (Urban Science Edition), vol. 23, no. 4, pp. 27-30, 2006. 